Abanico Agroforestal. Enero-Diciembre 2020; 2:1-14. http://dx.doi.org/10.37114/abaagrof/2020.4 Artículo Original. Recibido: 06/12/2019. Aceptado: 20/04/2020. Publicado: 25/04/2020.

\title{
Germinación in vitro e inducción de callo y raíz en Bursera laxiflora S. Watson
}

In vitro germination and induction of callus and root in Bursera laxiflora S. Watson

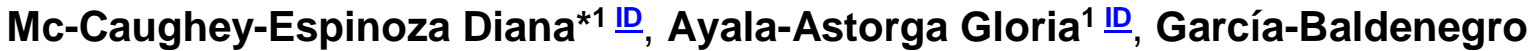

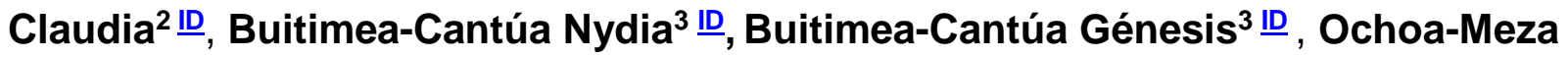 Andres $2 \underline{\text { ID}}$}

\begin{abstract}
1Departamento de Investigaciones Científicas y Tecnológicas de la Universidad de Sonora. México. ${ }^{2}$ Universidad Estatal de Sonora UES. Av. Ley Federal del Trabajo CP. 83100, Hermosillo Sonora. México. ${ }^{3}$ Tecnologico de Monterrey, Centro de Biotecnología-FEMSA, Escuela de Ingeniería y Ciencias, Campus Monterrey. Av. Eugenio Garza Sada 2501, Monterrey, N.L., C.P. 64849, México. ${ }^{4}$ Departamento de Agricultura y Ganadería de la Universidad de Sonora. México. diana.mccaughey@unison.mx, gloria.ayala@unison.mx, vanessagarciab81@gmail.com, nebc@tec.mx, genesis.vidal@tec.mx y
\end{abstract} andres.ochoa@unison.mx

\section{RESUMEN}

El Torote prieto (Bursera laxiflora S. Watson) es una especie endémica, forestal y medicinal de las zonas áridas y semiáridas del estado de Sonora. En el presente estudio se evaluó la germinación e inducción de callo y raíz de torote prieto a partir de plántulas cultivadas in vitro. Se utilizó como medio de crecimiento WPM al $50 \%$ de sales minerales, vitaminas y ácido indolbutírico (AIB) a diferentes concentraciones (0, 0.5, 1.0, 1.5 y $2.0 \mathrm{mgL}^{-1}$ ). Al utilizar 1.5 y $2.0 \mathrm{mgL}^{-1}$ de AIB se presentó un $70 \%$ de germinación. La contaminación fue de 5.0 a $27.5 \%$ y la altura de las plántulas fue de 6.67 a $10.1 \mathrm{~cm}$. Los callos presentaron alturas de 2.4 a $3.64 \mathrm{~mm}$ en hoja, 2.45 a $3.55 \mathrm{~mm}$ en tallo y en yema apical de 2.49 a $3.42 \mathrm{~mm}$. El ancho de los callos en hoja fue de 2.20 a $2.78 \mathrm{~mm}$, yema apical 2.13 a $2.22 \mathrm{~mm}$ y tallo 2.11 a $2.28 \mathrm{~mm}$. La inducción de raíz se presentó en las concentraciones de 0.5 a $2.0 \mathrm{mgL}^{-1}$ de AIB en los explantes de tallo y hoja excepto en yema apical. La aplicación de AIB estimula la inducción de callo y raíz en torote prieto.

Palabras clave: Bursera laxiflora, micropropagación, explantes, callos y raíz.

\begin{abstract}
Tight torote (Bursera laxiflora S. Watson) is an endemic, forest and medicinal species of the arid and semiarid areas of the state of Sonora. In the present study the germination and induction of callus and root of tight torote was evaluated from in vitro cultivated seedlings used as a medium of WPM growth in half of mineral salts, vitamins and indolbutyric acid (AIB) at different concentrations $(0,0.5,1.0,1.5$ and $2.0 \mathrm{mgL}$ 1). When using 1.5 and $2.0 \mathrm{mgL}-1$ of $\mathrm{AIB}, 70 \%$ germination occurred. The contamination was 5.0 to $27.5 \%$ and the height of the seedlings was 6.67 to $10.1 \mathrm{~cm}$. The calluses presented heights of 2.4 to $3.64 \mathrm{~mm}$ in leaf, 2.45 to $3.55 \mathrm{~mm}$ in stem and in apical bud of 2.49 to $3.42 \mathrm{~mm}$. The width of the calluses in leaf was of 2.20 to $2.78 \mathrm{~mm}$, apical bud 2.13 to $2.22 \mathrm{~mm}$ and stem 2.11 to $2.28 \mathrm{~mm}$. Root induction occurred in concentrations of 0.5 to $2.0 \mathrm{mgL}-1$ of AIB in stem and leaf explants except in apical bud. The application of AIB stimulates the induction of callus and root in tight torote.
\end{abstract}

Keywords: Bursera laxiflora, micropropagation, explants, calluses and root. 


\section{INTRODUCCIÓN}

La crio-conservación y regeneración de plantas in vitro es utilizada para conservar y micropropagar material vegetal específico, con el fin de llevar a cabo la conservación ex situ y permitir el desarrollo de la silvicultura clonal o de micropropagación (Martínez et al., 2003). Estas técnicas ofrecen una serie de ventajas como la posibilidad de producir un elevado número de plantas homogéneas y de una muy alta calidad fitosanitaria, en un menor plazo de tiempo y en espacios reducidos (Sharry et al., 2015).

El cultivo in vitro constituye una vía de propagación con resultados satisfactorios en los coeficientes de multiplicación y por las posibilidades de éxito de las plantaciones forestales. Los principales avances del cultivo de tejido in vitro han permitido la multiplicación de especies de interés, mediante organogénesis y embriogénesis somática (Daquinta et al., 2000; Barbón et al., 2011).

Las plantas maderables y no maderables representan un recurso genético forestal de importancia socioeconómica, agroforestal y científica (medicinal). Los recursos genéticos forestales son esenciales para mantener los diferentes ecosistemas presentes; sin embargo, están sujetos a las presiones paulatinas de los cambios climáticos y a una utilización insostenible (Yanchuk, 2002).

El género Bursera Jacquin ex L. (Burseraceae) se encuentra diversificado en distintas regiones de México y tiene registrado 82 taxas (Rzedowski et al., 2005). El torote prieto presenta propiedades medicinales, aunadas a los beneficios que esta especie aporta a los ecosistemas naturales, las cuales son explotados continuamente implicando la baja población y la regeneración de esta especie en su habitad natural; sin embargo, existen pocos trabajos relacionados a la propagación in vitro de especies forestales en el noroeste de México, lo que constituye una problemática para la conservación del recurso genético forestal.

Por lo anterior, es factible crear mecanismos viables para compensar los problemas de propagación de especies de interés forestal, utilizando la biotecnología en tejidos vegetales que permitan clonar especies sin cambiar el entorno natural del habitad de las especies; obteniendo plantas libres de patógenos y en menor tiempo (RebolledoCamacho et al., 2006; Delgado et al., 2008).

En los últimos años el uso de la biotecnología para la propagación in vitro de especies forestales se ha incrementado paulatinamente; no obstante, no existen trabajos relacionados con a la obtención de plantas in vitro de torote prieto a partir de plántulas de estériles.

El objetivo de este trabajo fue evaluar la germinación e inducción de callo y raíz de torote prieto a partir de plántulas cultivadas in vitro, utilizado como medio de crecimiento Woody Plant Medium (WPM/50) a la mitad de la concentración de sales minerales, vitaminas y ácido indolbutírico a diferentes concentraciones. 


\section{MATERIAL Y MÉTODOS}

La presente investigación se llevó a cabo en el laboratorio de cultivos de tejido del Departamento de Investigaciones Científicas y Tecnológicas de la Universidad de Sonora (DICTUS).

\section{Sitio de colecta}

El material vegetal fue recolectado en el Rancho Bella Vista, que se encuentra localizado a los $29^{\circ} 10^{\prime} 02.83^{\prime \prime}$ de Latitud Norte y los 110 $58^{\prime} 47.48 "$ de Longitud Oeste, a 277 msnm; con una precipitación media anual de $330 \mathrm{~mm}$ y temperatura promedio de $24^{\circ} \mathrm{C}$ (SAGARPA, 2010). Se colectaron semillas maduras de plantas vigorosas de torote prieto (Bursera Laxiflora), en el mes de septiembre de 2019.

\section{Preparación del medio de cultivo}

Se utilizó Woody Plant Medium (WPM/50) (Trigiano y Gray, 2011) como medio de cultivo. Este medio se utilizó a la mitad de su concentración de sales, constituido de sacarosa, agar y vitaminas, tales como tiamina y myo-inositol. La fitohormona que se utilizó fue el ácido indolbutírico a diferentes concentraciones, $\left(0,0.5,1.0,1.5\right.$ y $\left.2.0 \mathrm{mgL}^{-1}\right)$, el pH se ajustó a 5.7 con $\mathrm{NaOH}$, a una concentración $0.1 \mathrm{~N}$. La cámara de flujo laminar fue esterilizada con alcohol etílico al 99\%. Se utilizó $25 \mathrm{ml}$ de medio WPM por frasco de vidrio, tipo gérber. Por último se procedió a la esterilización en la autoclave modelo Sterilmatic, a $120^{\circ} \mathrm{C}$ de temperatura y con una presión de $15 / \mathrm{cm}^{2}$ durante 15 minutos.

\section{Germinación de semillas}

Las semillas se desinfectaron con alcohol etílico (70\%) durante 3 minutos, e hipoclorito de sodio ( $\mathrm{NaClO}$ ) (CLOROX® 15\% de cloro activo) durante 12 minutos, y añadiendo una gota de Tween 20. Aplicándose 3 enjuagues con agua desionizada, y posteriormente colocándolas en una mezcla de ácido cítrico y ascórbico durante 5 minutos, para posteriormente sembrarlas en el medio de cultivo WPM (Trigiano y Gray, 2011).

\section{Obtención de explantes}

Posteriormente a la germinación, se obtuvieron plántulas que presentaron todas las características morfológicas de planta silvestre. Estas plantas fueron subcultivadas utilizando explantes (yema apical, tallo y hojas), utilizando el $50 \%$ del medio WPM, adicionado con AIB. Para la siembra de los explantes obtenidos de las plántulas, se pasaron a la cámara de flujo laminar (Marca Edge Gard Hood); se utilizaron cajas Petri, bisturí y pinzas previamente esterilizados. Los cortes y obtención de segmento de hojas, yemas apicales y tallo (explantes) no requirieron ser desinfectados, siendo ya un material aséptico. 


\section{Condición del cultivo}

El cultivo se conservó en el cuarto de crecimiento en condiciones controladas, a una temperatura de $25^{\circ} \mathrm{C}$, con foto periodo de 16 horas de luz; presentando una intensidad luminosa de $30 \mu \mathrm{mol} . \mathrm{m}^{2} . \mathrm{s}^{-1}$ y 8 horas de oscuridad, con una temperatura de $25 \pm 2^{\circ} \mathrm{C}$.

\section{Variables a evaluar}

La evaluación fue por observación de manera directa, iniciando el tercer día después de la siembra de los explantes, para posteriormente realizar las evaluaciones cada séptimo día. La evaluación fue hasta los 30 días después de la siembra. Las variables que se evaluaron fueron: porciento de germinación (\%), altura de plántulas $(\mathrm{cm})$, porciento de contaminación (\%), altura del callo (\%), ancho del callo $(\mathrm{cm})$ y número de raíces. De acuerdo al ISTA (2019), se llevó a cabo el porcentaje de germinación. Para las mediciones de callos presentes en los explantes se utilizó un vernier marca Mitutoyo Absolute Modelo CD-6CSX N de Serie 06401649 de 6".

\section{Análisis estadístico}

En este trabajo de investigación se utilizó un diseño completamente al azar, y un arreglo factorial de $5 \times 3$ con 10 repeticiones. Se llevó a cabo un análisis de varianza (ANDEVA), con un nivel de significancia de $\mathrm{P}<0.05$, y una comparación de medias por Tukey. Para el análisis de datos se empleó el programa el paquete estadístico JMP versión 9.0.1 (Statistical Analysis System, SAS Institute Inc., 2011).

\section{RESULTADOS Y DISCUSIÓN}

La germinación in vitro de las semillas de torote prieto (Bursera laxiflora), inició al noveno día y concluyó su evaluación a los 21 días después de su siembra. No se presentaron diferencias significativas $(P \geq 0.05)$ al utilizar las concentraciones de 2, 1.5, 1.0 y $0.5 \mathrm{mgL}^{-}$ ${ }^{1}$ de AIB, mostrando un 45 a $70 \%$ de germinación; excepto el control (sin tratamiento), con un $30 \%$ de germinación en el medio de cultivo utilizado (WPM/50) a diferentes concentraciones de AIB $\left(0,0.5,1.0,1.5\right.$ y $\left.2.0 \mathrm{mgL}^{-1}\right)$. No se presentaron diferencias significativas $(P \geq 0.05)$ en el porcentaje de semillas no germinadas, mostrando un 22.5 a 42.5\%.

Es importante señalar que en este estudio no se presentaron plántulas anormales, por lo tanto no existen diferencias significativas, ver figura 1 y tabla 1 Kameswara et al., (2007). Hace énfasis que la germinación determina el crecimiento del embrión, la protrusión de la radícula y testa.

En lo que respecta a este estudio, las plántulas se consideraron con crecimiento normal al presentar raíz y brotes y órganos importantes para su desarrollo. Al presentar dichos órganos las plántulas muestran deficiencias que repercutirá en la calidad de las plánulas (AOSA, 2005). 


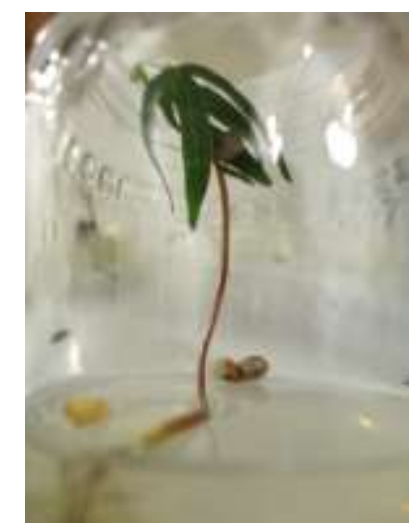

Figura 1. Germinación in vitro de Bursera laxiflora S. Watson

Es muy favorable el porcentaje de germinación obtenido en este estudio para las semillas de torote prieto, debido a que esta especie de árbol es muy importante para el estado de SonoraM; sin embargo, los resultados del porcentaje de germinación obtenidos en este estudio no coinciden con los obtenidos por (Pinta et al., 2017), quienes utilizaron el medio de cultivo MS (Murashige y Skoog (1962); estos investigadores reportaron $11.11 \%$ de germinación de Bursera graveolens (KUNTH), con el tratamiento de escarificación mecánica y $0.5 \mathrm{mg} / \mathrm{L}$ de ácido giberelico $\left(\mathrm{AG}^{3}\right)$.

Resultados similares han sido reportados por (Bonfil-Sanders et al., 2008), quienes obtuvieron del 30 al $60 \%$ de germinación in situ en semillas de Bursera bicolor, Bursera copallifera y Bursera glabrifolia, almacenadas durante seis meses en refrigeración a $5^{\circ} \mathrm{C}$. Por lo tanto, los resultados muestran que la propagación de algunas especies de Bruceras incluyendo a Burcera laxiflora, presentan dificultades para su germinación, al no alcanzar valores del $80 \%$ de germinación.

Recientemente, Mero et al., (2017), evaluaron el efecto de reguladores de crecimiento auxínico a diferentes concentraciones, para la regeneración de tejido vegetal en estaquillas de Bursera graveolens, obteniendo formación de brotes y callo, excepto en raíz, al utilizar 800 ppm de AIB a los 60 días después de la siembra. Desafortunadamente existen poca información en la literatura con respecto a la germinación de Burseras; los reportes muestran resultados con bajo porcentaje de germinación (Andrés-Hernández y Espinosa-Organista, 2002). Similarmente (Ray y Brown, 1995; Ortiz-Pulido y Rico-Gray, 2006), reportaron porcentajes de germinación en condiciones naturales, más bajos que los obtenidos a nivel laboratorio.

Por lo anteriormente descrito sobre la dificultad que presenta esta leñosa para su propagación en forma natural y/o artificial, las técnicas de cultivo de tejidos in vitro permiten nuevas técnicas para la propagación de cultivos de crecimiento lento y la criopreservación de tejidos (Engelmann, 2000; Dixit et al., 2004; Wang et al., 2005). El bajo porcentaje de germinación de las semillas de esta especie se debe a que no están 
en condiciones de germinar rápidamente, después de ser colectadas; las semillas necesitan un periodo de reposo, de carácter transitorio, de seis meses aproximadamente (Morillo et al., 2017).

Tabla 1. Germinación, contaminación y altura de plántulas in vitro de semillas de torote prieto (Bursera laxiflora S. Watson)

\begin{tabular}{ccccc}
\hline $\begin{array}{c}\text { Tratamiento } \\
\text { AIB mgL }\end{array}$ & $\begin{array}{c}\text { Semillas } \\
\text { germinadas (\%) }\end{array}$ & $\begin{array}{c}\text { Semillas no } \\
\text { Germinadas (\%) }\end{array}$ & $\begin{array}{c}\text { Contaminación } \\
(\%)\end{array}$ & $\begin{array}{c}\text { Altura de } \\
\text { plántulas }(\mathbf{c m})\end{array}$ \\
\hline 0 & $30.0 \pm 24.49^{\mathrm{b}}$ & $42.5 \pm 17.07^{\mathrm{a}}$ & $27.5 \pm 22.17^{\mathrm{a}}$ & $6.67 \pm 4.45^{\mathrm{a}}$ \\
0.5 & $45.0 \pm 12.90^{\mathrm{a}}$ & $32.5 \pm 22.17^{\mathrm{a}}$ & $22.5 \pm 12.58^{\mathrm{a}}$ & $9.05 \pm 0.61^{\mathrm{a}}$ \\
1.0 & $67.5 \pm 9.57^{\mathrm{a}}$ & $22.5 \pm 9.57^{\mathrm{a}}$ & $10.0 \pm 0.00^{\mathrm{a}}$ & $10.01 \pm 0.14^{\mathrm{a}}$ \\
1.5 & $70.0 \pm 8.16^{\mathrm{a}}$ & $22.5 \pm 5.00^{\mathrm{a}}$ & $7.5 \pm 5.00^{\mathrm{a}}$ & $10.01 \pm 0.25^{\mathrm{a}}$ \\
2.0 & $70.0 \pm 8.16^{\mathrm{a}}$ & $25.0 \pm 5.77^{\mathrm{a}}$ & $5.0 \pm 5.77^{\mathrm{a}}$ & $10.21 \pm 0.24^{\mathrm{a}}$
\end{tabular}

Medias con letras iguales dentro de la misma columna indican que no hay diferencias significativas $(\mathrm{P}<0.05)$. Los datos presentados son la media de 10 repeticiones con 3 muestras cada frasco por tratamiento.

\section{Altura de las plántulas}

No se presentaron diferencias significativas $(P \geq 0.05)$ en la variable de altura de las plántulas, con respecto a las concentraciones que se manejaron en este trabajo, mostrando alturas de 6.67 a $10.21 \mathrm{~cm}$ respectivamente. Las plántulas de torote prieto (Bursera laxiflora), mostraron buen crecimiento y desarrollo adecuado. No se encontraron investigaciones publicadas que evalúen la micropropagación in vitro de Burseras, ver tabla 1 y figura 2 .

\section{Contaminación}

La contaminación de las semillas fue del 5 al 27.5\%, ocasionada principalmente por hongos ambientales y bacterias. No presentaron diferencias significativas $(P \geq 0.05)$ en esta variable al utilizar las diferentes concentraciones de WPM/50, ver tabla 1 . La contaminación de las semillas de esta investigación son inferiores a los obtenidos por Pinta et al., (2017), quienes reportaron hasta un 93\% de contaminación in vitro en los explantes de Bursera graveolens (Kunth).

Los cultivos in vitro en general presentan dos características fundamentales: la asepsia (ausencia de microorganismos contaminantes de hongos y bacterias), y control de factores que perturben el crecimiento, como las condiciones ambientales de cultivo. Por lo tanto se requiere de una correcta detección de estas fuentes e identificar el tipo de microorganismo; estos son aspectos importantes para el éxito de los cultivos y prevenir la contaminación primaria en los cultivos in vitro provienen de la planta donadora (George et al., 2008; Levitus et al., 2010; Sharry et al., 2015). 


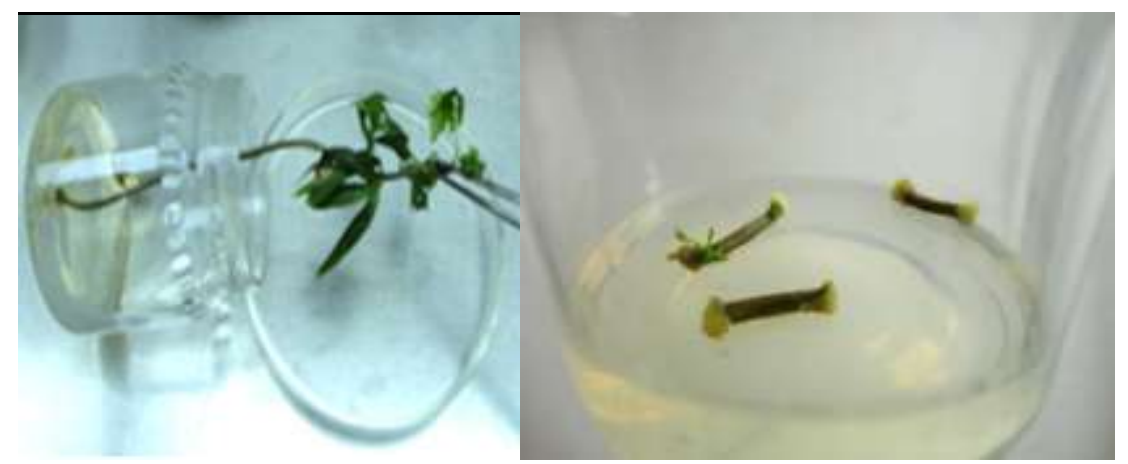

Figura 2. Obtención de explantes, tallos con callo y brotes

Para minimizar el problema de la contaminación, se han aplicado desinfectantes y/o mezclas de fungicidas y bactericidas en explantes (Das et al., 2010; Jayakrishna et al., 2011). Similarmente, Pérez-Alonso et al., (2015), mencionan la importancia de la colecta del material vegetal de acuerdo la época del año, influencia de las temperaturas, precipitaciones y los altos índices de contaminación; lo cual sería vital para la disminución de la contaminación.

\section{Callo y raíz en Bursera laxiflora}

El porcentaje de callo presente en los explantes de acuerdo a los tratamientos utilizados con AIB, mostró diferencias significativas con respecto al tratamiento cero (control), sin $\mathrm{mgL}^{-1}$ de AIB. El promedio más alto de formación de callo se presentó al utilizar el tratamiento $1.5 \mathrm{mgL}^{-1}$ de AIB, en los tres explantes (hoja, yema apical y tallo), al obtener un $80 \%$ de callos, seguida de esta se encuentra el tratamiento $2.0 \mathrm{mgL}^{-1}$ de AIB, con $78 \%$ de callo, $1.0 \mathrm{mgL}^{-1}$ de AIB, con $77 \%$; y por último la $0.5 \mathrm{mgL}^{-1}$ de $\mathrm{AIB}$, con $7.2 \%$. El uso de AIB estimula de manera positiva el crecimiento de callo a los 30 días.

En la tabla 2, se muestra la inducción del callo presente en hojas, yema apical y tallo a diferentes concentraciones de ácido indolbutirico (AIB). Se presentaron diferencias significativas $(\mathrm{P} \leq 0.05)$ con respecto a la altura y ancho del callo. A la concentración de $2.0 \mathrm{mgL}^{-1}$ de AIB se presentaron mayores valores de altura en hoja de $3.64 \mathrm{~mm}$ y tallo $3.55 \mathrm{~mm}$.

Sin embargo, no se presentaron diferencias significativas $(P \geq 0.05)$ en los valores de yema apical a las concentraciones de 1.5 y $2.0 \mathrm{mgL}^{-1}$ de AIB con 3.42 y $2.72 \mathrm{~mm}$, respectivamente. Un comportamiento similar a la altura del callo se observó en el ancho del callo en los explantes. A la concentración de $2.0 \mathrm{mgL}^{-1}$ de AIB se presentaron mayores anchos de hoja $(2.78 \mathrm{~mm})$ y tallo $(2.68 \mathrm{~mm})$. En la yema apical no se presentaron diferencias significativas en las concentraciones de 0.5 y $2.0 \mathrm{mgL}^{-1}$ de AIB con $2.21 \mathrm{~mm}$ y $2.22 \mathrm{~mm}$, respectivamente. 
Tabla 2 Inducción de callo en explantes de torote prieto (Bursera laxiflora S. Watson)

\begin{tabular}{cllcccc}
\hline Tratamiento & \multicolumn{3}{c}{ Altura del callo $(\mathrm{mm})$} & \multicolumn{2}{c}{ Ancho del callo $(\mathrm{mm})$} \\
\cline { 2 - 6 }${\text { AlB } \mathrm{mgL}^{-1}}^{\text {Hoja }}$ & Tallo & Yema apical & Hoja & Tallo & Yema apical \\
\hline 0 & $0.00 \pm 0.00^{\mathrm{d}}$ & $0.00 \pm 0.00^{\mathrm{d}}$ & $0.00 \pm 0.00^{\mathrm{c}}$ & $0.00 \pm 0.00^{\mathrm{d}}$ & $0.00 \pm 0.00^{\mathrm{c}}$ & $0.00 \pm 0.00^{\mathrm{c}}$ \\
0.5 & $2.40 \pm 0.08^{\mathrm{c}}$ & $2.45 \pm 0.16^{\mathrm{c}}$ & $2.49 \pm 0.19^{\mathrm{b}}$ & $2.20 \pm 0.08^{\mathrm{c}}$ & $2.11 \pm 0.60^{\mathrm{b}}$ & $2.13 \pm 0.03^{\mathrm{b}}$ \\
1.0 & $2.69 \pm 0.14^{\mathrm{bc}}$ & $2.62 \pm 0.12^{\mathrm{c}}$ & $2.73 \pm 0.26^{\mathrm{b}}$ & $2.36 \pm 0.08 \mathrm{~b}^{\mathrm{c}}$ & $2.13 \pm 0.04^{\mathrm{b}}$ & $2.13 \pm 0.04^{\mathrm{b}}$ \\
1.5 & $3.09 \pm 0.23^{\mathrm{b}}$ & $3.06 \pm 0.17^{\mathrm{b}}$ & $3.42 \pm 0.49^{\mathrm{a}}$ & $2.53 \pm 0.08^{\mathrm{ab}}$ & $2.27 \pm 0.03^{\mathrm{a}}$ & $2.21 \pm 0.01^{\mathrm{a}}$ \\
2.0 & $3.64 \pm 0.31^{\mathrm{a}}$ & $3.55 \pm 0.21^{\mathrm{a}}$ & $2.72 \pm 0.19^{\mathrm{a}}$ & $2.78 \pm 0.24^{\mathrm{a}}$ & $2.28 \pm 0.02^{\mathrm{a}}$ & $2.22 \pm 0.01^{\mathrm{a}}$
\end{tabular}

Medias con letras iguales dentro de la misma columna indican que no hay diferencias significativas $(\mathrm{P}<0.05)$. Los datos presentados son la media de 10 repeticiones con 3 muestras cada frasco por tratamiento.

Es importante señalar que a bajas concentraciones de AIB (0.5 y $\left.1.0 \mathrm{mgL}^{-1}\right)$, en yema apical, se indujeron callos con menores alturas y ancho. En tallo también se presentaron diferencias significativas $(\mathrm{P} \geq 0.05)$, con respecto a las concentraciones evaluadas; siendo la mejor la dosis de $2.01 .0 \mathrm{mgL}^{-1}$, en ambas mediciones (alto y ancho de callo), ver tabla 2 y figura 3. Con respecto al control (sin AIB), no se presentó altura y ancho de callo; esto nos indica que los explantes de Bursera laxiflora (hoja, yema apical y tallo) requieren de una fitohormona que estimule la inducción de callogénesis. Los callos obtenidos independientemente de la concentración y explante en este estudio, presentaron una consistencia firme y de color blanco crema, tornándose a un verde claro.

De acuerdo a la presencia del número de raíz en los explantes (hoja, yema apical y tallo) de Bursera laxiflora, se presentaron diferencias significativas $(P \leq 0.05)$ en el tallo, a una concentración de $2.0 \mathrm{mgL}^{-1}$ de AIB $(2.7 \mathrm{~cm})$. A la concentración de $0.5 \mathrm{mgL}^{-1}$ de AIB, se presentaron los menores valores de tallo y hoja $(1.00$ y $0.25 \mathrm{~cm})$, respectivamente. En lo que respecta a la yema apical no se presentaron raíces en concentraciones más bajas (0.5 y $1.0 \mathrm{mgL}^{-1}$ de AIB). En los explantes sin AIB (control), no se presentó crecimiento de raíz en los diferentes explantes de tallo, hoja y yema apical, ver tabla 3 y figura 3.

Tabla 3. Inducción de raíz en explantes de torote prieto (Bursera laxiflora S. Watson)

\begin{tabular}{cccc}
\hline $\begin{array}{c}\text { Tratamiento } \\
\text { mgL }^{-1} \text { AlB }\end{array}$ & Toja & Tallo & Yema apical \\
\cline { 2 - 4 } & $0.00 \pm 0.00^{\mathrm{c}}$ & $0.00 \pm 0.00^{\mathrm{a}}$ & $0.00 \pm 0.00^{\mathrm{a}}$ \\
0 & $1.00 \pm 0.81 \mathrm{~b}^{\mathrm{c}}$ & $0.25 \pm 0.50^{\mathrm{a}}$ & $0.00 \pm 0.00^{\mathrm{a}}$ \\
1.0 & $1.75 \pm 0.50^{\mathrm{ab}}$ & $0.50 \pm 0.57^{\mathrm{a}}$ & $0.00 \pm 0.00^{\mathrm{a}}$ \\
1.5 & $1.25 \pm 0.57^{\mathrm{a}}$ & $0.50 \pm 0.57^{\mathrm{a}}$ & $0.25 \pm 0.50^{\mathrm{a}}$ \\
2.0 & $2.7 \pm 0.50^{\mathrm{a}}$ & $0.50 \pm 0.57^{\mathrm{a}}$ & $0.25 \pm 0.50^{\mathrm{a}}$
\end{tabular}

Medias con letras iguales dentro de la misma columna indican que no hay diferencias significativas $(\mathrm{P}<0.05)$. Los datos presentados son la media de 10 repeticiones con 3 muestras cada frasco por tratamiento.

Los explantes evaluados en este experimento no presentaron embriogénesis directa; sin embargo, produjeron tejido calloso sin el tejido embriogénico, desarrollando paulatinamente más cantidad de masa proembriogénica con el transcurso del tiempo de incubación. Estos resultados son similares a los obtenidos por Kryvenki et al., (2008), 
quienes obtuvieron callo en todos los tratamientos, utilizando como medio de cultivo Murashige y Skoog (MS) semisólido en Stevia rebaudiana Bert, excepto en el control (sin medio de cultivo).

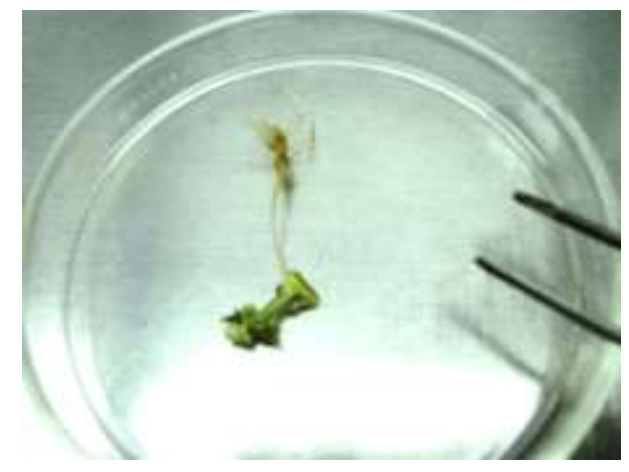

Figura 3. Callo y raíz en tallo

En relación al porcentaje de callos presentes en los explantes utilizados en este trabajo (yema apical, tallo y hoja), fueron mayores a los obtenidos por Rodríguez et al., (2014), ellos utilizaron como medio de cultivo Murashige y Skoog (MS), suplementado con 0.5 $\mathrm{mg} \mathrm{L}^{-1}$ de ácido naftalenacético (ANA), en explantes de hipocotilo (62, 62, 74 y $64 \%$ ).

De acuerdo a Smith (2012), el tipo de callo presente es un indicador importante sobre la ruta morfogénica a seguir, independiente del color del callo; estos indican que los callos organogénicos proceden de callos nodulares color verde o de apariencia oxidada, como los fenólicos (Bandyopadhyay et al.,1999; Ainsley et al., 2000). El cambio de aspecto de los callos conforme se cultivan en el tiempo ha sido reportado por Larson et al., (2006). Al respecto Shiram et al., (2008) señalan que altas concentraciones de auxina o citoquininas estimulan la producción de callo y que su aspecto está relacionado al tipo de hormona utilizada durante su inducción.

Varias investigaciones han reportado que las auxinas/citoquinina favorecen la inducción de callos en Pinus strobus L., así como en híbridos de Eucalyptus granáis y Eucalyptus urophylla o únicamente auxinas originando callos caulogénicos (Tang y Newton, 2005; Hajari et al., 2006). En otros casos, como en Eucaliptus nitens, E. globulus y E. camaldulensis, la inducción por auxinas ha generado callos embriogénicos (Bandyopadhyay et al., 1999; Gopalakrishnan et al., 2010).

\section{CONCLUSIONES}

La germinación in vitro de la semilla de torote prieto (Bursera laxiflora S. Watson), se puede promover con la aplicación de ácido indolburtirico (AIB), en concentraciones desde1.5 o $2.0 \mathrm{mgL}^{-1}$; utilizando medio de cultivo WPM/50. Las plantas germinadas in vitro produjeron brotes y raíces, presentando características morfológicas de planta silvestre. El uso del ácido indolburtirico a las concentraciones de 1.0, 1.5 y $2.0 \mathrm{mgL}^{-1}$ promueven la formación de callogénesis, fiable con color blanco, tornándose a verde 
claro y organogénesis en explantes de torote prieto (Bursera laxiflora S. Watson). Estos resultados indican que es posible estimular el desarrollo de callos y raíces para la conservación del torote prieto (Bursera laxiflora S. Watson), por ser una especie endémica del estado de Sonora.

\section{AGRADECIMIENTO}

A Yeimi C. Mc Caughey Espinoza, por su gran apoyo en la recoleccion de las semillas, para la realizacion de este trabajo de investigacion.

\section{LITERATURA CITADA}

AINSLEY P, Collins G, Sedgley M. 2000. Adventitious shoot regeneration from leaf explants of almond (Prunus dulcis Mill.). In vitro Cellular and Developmental BiologyPlant. 36: 470-474. https://doi.org/10.1007/s11627-000-00845https://link.springer.com/article/10.1007/s11627-000-0084-5

ANDRÉS-HERNÁNDEZ A, Espinoza-Organista D. 2002 Morfología de plántulas de Bursera Jacq ex L. (Burseraceae) y sus implicaciones filogenéticas. Boletín de la Sociedad Botánica de México. 70:5-12. ISSN: 0366-2128. https://doi.org/10.17129/botsci.1652

AOSA. Association of Official Seed Analysts. 2005. Rules fortesting seeds. Association of Official Seed Analysts, USA. https://www.analyzeseeds.com/about-us/

BANDYOPADHYAY S, Karen C, Gillian R, John D. 1999. Efficient plant regeneration from seedling explants of two commercially important temperate eucalypt species Eucaliptus nitens and E. globulus. Plant Science. 140: 189-198. https://doi.org/10.1016/S01689452(98)00221-0

BARBÓN R, Borroto I, Pérez MOL. 2011. Embriogénesis somática de Swietenia mahagoni (L.) Jacq. En medios de cultivo semisólidos. Revista Forestal Baracoa. AGRIS: International Information System for the Agricultural Science and Technology ISSN: 0138-6441. http://agris.fao.org/agris-search/search.do?recordID=CU2011800203

BONFIL-SANDERS C, Cajero-Lázaro I, Evans RY. 2008. Germinación de semillas de seis especies de Bursera del centro de México. Agrociencia. 42(7):827-834. http://www.scielo.org.mx/scielo.php?script=sci_arttext\&pid=S140531952008000700009\&lng=es\&tIng=es.

DAQUINTA GM, Ramos L, Lezcano Y, Rodríguez R, Escalona M. 2000. Algunos elementos en la micropropagación de la Teca. Rev. Biotecnología Vegetal. 1: 39-44. ISSN: 1609-1841. https://www.cabdirect.org/cabdirect/abstract/20023071989 
DAS AP, Mukherjee TB. 2010. High frequency micropropagation of Aloe vera L. Burm. F. as a low cost option towards commercialization. Plant Cell Tiss Organ Cult. 20 (1): 29-35. https://doi.org/10.3329/ptcb.v20i1.5962

DELGADO MF, Cuba M, Hechenleitner P, Thiers O. 2008. Propagación vegetativa de taique (Desfontainia spinosá) y tepa (Laureliopsis philippiana) con fines ornamentales. Bosque (Valdivia). 29(2):120-126.

https://scielo.conicyt.cl/scielo.php?script=sci_arttext\&pid=S0717-92002008000200004

DIXIT S, Ahuja S, Narula A, Srivastava P. 2004. Cryopreservation: A Potential Tool for Long-term Conservation of Medicinal Plants. p. 278 - 288. In: Srivastava P, Narula A, Srivastava S. (eds) Plant Biotechnology and Molecular Markers. Springer, Dordrecht. ISBN 978-1-4020-1911-1. https://doi.org/10.1007/1-4020-3213-7_19

ENGELMANN F. 2000. Cryopreservation of tropical plant germplasm: Japan International Research Center for Agricultural Sciences (JIRCAS), Tsukuba. (Japan); International Plant Genetic Resources Instit., (IPGRI), Rome (Italy). Pp. 8-15. ISBN 92-9043-428-7

GEORGE EFA, Hall M, Geert-George De Klerk. 2008. Plant Tissue Culture ProcedureBackground. En: George EF, Hall MA, de Klerk GJ (Eds) Plant Propagation by Tissue Culture $3^{\text {rd }}$. Edition. Vol 1. The Background. Pp. 1-28. Springer. Dordrecht.

GOPALAKRISHNAN Nair, Prakash Gurumurthi K. 2010. Effects of type of explant and age, plant growth regulators and medium strength on somatic embryogenesis and plant regeneration in Eucalyptus camaldulensis. Plant Cell Tissue and Organ Culture. 13-20. https://doi.org/10.1007/s11240-009-9611-1.

HAJARI E, Watt M, Mycock D, McAlister B. 2006. Plant regeneration from induced callus of improved Eucalyptus clones. South African Journal of Botany. 72: 195 - 201. https://doi.org/10.1016/j.sajb.2005.07.003

ISTA [International Seed Testing Association]. 2019. International Rules for Seed Testing. Zurich, Switzerland: Seed Science \& Technology. ISBN: 3906549275

JAYAKRISHNA C, Karthik C, Barathi S, Kamalanathan D, ArulSelvi P. 2011. In vitro propagation of Aloe barbadensis Miller, a miracle herb. Research in Plant Biology. 1(5): 22-26. ISSN: 2231-5101.

https://www.academia.edu/5078372/In_vitro_propagation_of_Aloe_barbadensis_Miller_ a_miracle_herb

KAMESWARA Rao N, Hanson J, Ehsan Dulloo M, Ghosh K, Novell D, Larinde M. 2007. "Manual para el Manejo de Semillas en Bancos de Germoplasma". Manuales para Bancos de Germopasma $\mathrm{N}^{\circ}$ 8. Bioversity International, Roma, Italia. 
https://www.bioversityinternational.org/fileadmin/_migrated/uploads/tx_news/Manual_par a_el_manejo_de_semillas_en_bancos_de_germoplasma_1261_01.pdf

KRYVENKI M, Kosky RG, Guerrero D, Dominguez M, Reyes M. 2008. Obtención de callos con estructuras embriogénicas de Stevia rebaudiana Bert. en medios de cultivo semisólido. Biotecnología Vegetal. 8(2): 91-98. ISSN 2074-8647. https://revista.ibp.co.cu/index.php/BV/article/view/341/html

LARSON CG, Gómez C, Sánchez-Olate M, Ríos D. 2006. Inducción de caulogénesis indirecta en Eucalyptus globulus. Bosque (Valdivia). 27(3):250-257. https://dx.doi.org/10.4067/S0717-92002006000300004

LEVITUS G, Echenique V, Rubinstein C, Hopp E, Mroginski L. 2010. Biotecnología y mejoramiento vegetal II. Instituto Nacional de Tecnología Agropecuaria, Argentina. 258 phttp://intainforma.inta.gov.ar/wp-content/uploads/2010/09/bio_WEB.pdf

MARTÍNEZ R, Azpiroz HS, Rodríguez J, Cetina VM, Gutiérrez MA. 2003. Aplicación de la biotecnología en los recursos genéticos forestales. Revista Chapingo. Serie Ciencias Forestales y del Ambiente. 9(1):17-34. ISSN 2007-3828. https://www.redalyc.org/pdf/629/62990103.pdf

MERO Jalca Otto F, Cuásquer Fuel E, García Lucas LM, Ramos Rodríguez MP, Jiménez González A. 2017. Efecto de reguladores de crecimiento tipo auxínico para la regeneración de tejido vegetal en Bursera graveolens. Revista Cubana de Ciencias Forestales. 5(3):259-269. ISSN: 1996-2452 RNPS: 2148. https://dialnet.unirioja.es/servlet/articulo?codigo $=62220$

MORILLO Infante Luis F, Eras Guamán Víctor H, Moreno Serrano J, Minchala Patiño J, Muñoz Chamba L, Yaguana Arévalo M, Angamarca Ruth P, Valarezo Ortega Cristian, Sinche Freire M. 2017. Estudio Fenológico y Propagación de Bursera graveolens (Kunth) en la Comunidad de Malvas, Cantón Zapotillo, Provincia de Loja. Rev. Bosques latitud Cero. 6(2):10-14: ISSN 2528-7818.

https://revistas.unl.edu.ec/index.php/bosques/article/view/222

MURASHIGE T, Skoog F. 1962. A revised medium for rapid growth and bio assays with tobacco tissue cultures. Physiologia plantarum. 15: 473-497. http://priede.bf.lu.Iv/grozs/AuguFiziologijas/Augu_audu_kulturas_MAG/literatura/03_Mur ashige\%20Scoog1962.pdf

ORTIZ-PULIDO R, Rico-Gray V. 2006. Seed dispersal of Bursera fagaroides (Burseraceae): the effect of linking environmental factors. The Southwestern Naturalist. 51: 11-21. https://www.jstor.org/stable/3672707?seq=1 
PÉREZ-ALONSO Naivy, Capote Alina, Pérez Anabel, Gómez Leticia, Jiménez Elio. 2015. Establecimiento y multiplicación in vitro de brotes de Aloe vera L. Biotecnología Vegetal. 15(2):85-95. ISSN 2074-8647. https://revista.ibp.co.cu/index.php/BV/article/view/14/494

PINTA Diego M, Eras-Guamán VH, González-Zaruma DU, Moreno-Serrano J, MinchalaPatiño JE, Yaguana-Arévalo M, Poma-Angamarca RA, Valarezo-Ortega CO, SincheFreire MG. 2017. Procesos biotecnológicos para la proliferación y enraizamiento in vitro de Bursera graveolens (Kunth) Triana \& planch (palo santo). Provenientes del bosque seco de la provincia de Loja. Bosques Latitud Cero. 6(1). ISSN 2528-7818. https://revistas.unl.edu.ec/index.php/bosques/article/view/178/174

RAY GJ, Brown BJ. 1995. Evaluation of tree propagation techniques. Restoration Ecology. 3:86-94. https://doi.org/10.1111/j.1526-100X.1995.tb00081.x

REBOLLEDO-CAMACHO V, Aparicio-Rentera A, Cruz-Jiménez H. 2006. Estudio preliminar para la propagación in vitro de dos especies de pinos. Forestal Veracruzana. 8(2):27-32.

https://www.researchgate.net/publication/242633141_estudio_preliminar_para_la_propa gacion_in_vitro_de_dos_especies_de_pinos

RODRÍGUEZ Beraud MM, Latsague Vidal MI, Chacón Fuentes MA, Astorga Brevis PK. 2014. Inducción in vitro de callogénesis y organogénesis indirecta a partir de explantes de cotiledón, hipocótilo y hoja de Ugni molinae. Bosque (Valdivia). 35(1):111118. https://dx.doi.org/10.4067/S0717-92002014000100011

RZEDOWSKI J, Medina Lemos R, Calderón de Rzedowski G. 2005. Inventario del conocimiento taxonómico, así como de la diversidad y del endemismo regionales de las especies mexicanas de Bursera (Burseraceae). Acta Botánica Méx. 70: 85-111. ISSN: 0187-7151. https://doi.org/10.21829/abm70.2005.989

SAGARPA. Secretaria de Ganadería Agricultura, Rural, Pesca y Alimentación. 2010. Diagnóstico Sectorial Agropecuario, Pesquero y Recursos Naturales del Estado de Sonora. Pp. 52.

http://smye.info/pagina/documentos/sistemas/eval2014/resultados2014/PDF2/SON/Disg nostico_20_octubre_2010.pdf

SHARRY S, Adema M, Abedini W. 2015. Plantas de probeta: manual para la propagación de plantas por cultivo de tejidos in vitro. Coordinación general: Sandra Sharry; Marina Adema; Walter Abedini. 1a ed. adaptada. Universidad Nacional de La Plata. pp. 240. ISBN 978-950-34-1254-1. 
SHRIRAM V, Kumar V, Shitole M. 2008. Indirect Organogenesis and Plant Regeneration in Helicteres isora L., an Important Medicinal Plant. In Vitro Cellular \& Developmental Biology. 44(3):186-193. https://doi.org/10.1007/s11627-008-9108-3.

SMITH R. 2012. Plant tissue culture: Techniques and experiments. Londres, UK. Academic Press Elsevier. Pp. 208. ISBN: 9780124159853 https://www.sciencedirect.com/book/9780124159204/plant-tissue-culture

SAS. Statistical Analysis System, Institute Inc. 2011. JMP versión 9.0.1. Statistical Discovery. From SAS. USA: Author. A Business Unit of SAS Campus Drive Cary, NC 27513.

TANG W, Newton RJ. 2005. Plant regeneration from callus cultures derived from mature zygotic embryos in white pine (Pinus strobes L.). Plant Cell Reports. 24(1):1-9. https://doi.org/10.1007/s00299-005-0914-3.

TRIGIANO RN, Gray DJ. 2011. Plant tissue culture, development, and biotechnology. Eds. CRC Press Boca Raton, Florida, USA. Pp. 359-364. ISBN 9781420083262

WANG YL, Fan MJ, Liaw SL. 2005. Cryopreservation of in vitro-grown shoot tips of papaya (Carica papaya L.) by vitrification. Botanical Bulletin of the Academia Sinica. 46:29-34. https://ejournal.sinica.edu.tw/bbas/content/2005/1/Bot461-04.html

YANCHUK A. 2002. Papel e implicaciones de la biotecnología en el sector forestal. Recursos Genéticos Forestales. FAO. AGRIS: International Information System for the Agricultural Science and Technology. UNASYLVA. 204:52-61. ISSN 1020444X.http://agris.fao.org/agris- search/search.do?recordID=XF2003414013

Publica tus resultados de investigaciones en las revistas abanico. https://abanicoacademico.mx/revistasabanico 